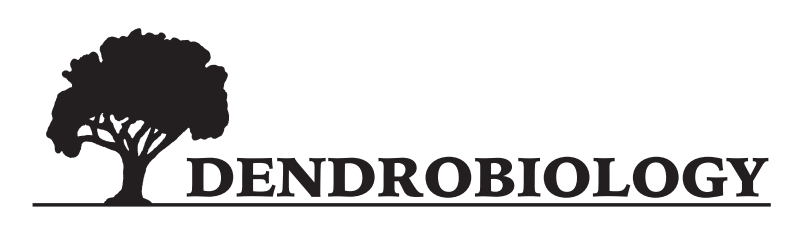

2019, vol. 81, 22-30

http://dx.doi.org/10.12657/denbio.081.003

\author{
Aleksandra Maria Staszak, Emilia Pers-Kamczyc, \\ Ewelina Anna Klupczyńska, Tomasz Andrzej Pawłowski*
}

\title{
Expression of abscisic and gibberellic acid signalling factors in Fagus sylvatica L. seeds during dormancy breaking and germination
}

Received: 4 January 2019; Accepted: 5 April 2019

\begin{abstract}
European beech seeds are characterised by deep physiological dormancy and to germinate, they require several weeks of stratification at $3^{\circ} \mathrm{C}$. Seed dormancy is under hormonal regulation, but the details of how hormones regulate deep dormancy in trees remain not yet well elucidated. We hypothesised that the mechanism of seed dormancy breaking is differentially regulated according to depth of dormancy. Expression of ABI5 and 14-3-3, members of the abscisic acid pathway, and RGL2, a member of gibberellic acid pathways, were examined at the protein and mRNA levels during dormancy alleviation of beech seeds. Unlike in non-deep dormant seeds, ABI5, 14-3-3 and RGL2 were present during nearly all periods of cold stratification in beech seeds, but during dormancy breaking and germination these proteins nearly disappeared. Relative abundances of $A B I 5$ and 14-3-3 transcripts were the highest in dormant dry seeds, and during stratification it decreased gradually. We suppose that during stratification, de novo translation of proteins on the basis of deposited mRNA occurred. On the base of our research we can conclude that the seed dormancy breaking mechanism differs according to seed's dormancy depth.
\end{abstract}

Keywords: ABI5, RGL2, 14-3-3, plant hormones, tree

Address: A. M. Staszak, E. Pers-Kamczyc, E. A. Klupczyńska, T. A. Pawłowski, Institute of Dendrology, Polish Academy of Sciences, Parkowa 5, 62-035 Kórnik, Poland, e-mail: tapawlow@man.poznan.pl

\section{Introduction}

Dormancy is an adaptive seed trait that regulates germination, and is characteristic of plant species growing in temperate climate zones (Baskin \& Baskin, 2004). It protects seeds against germination in unsuitable conditions, allowing for further growth and seedling establishment (Black et al., 2008). Deep physiological dormancy characterises the seeds of tree species, such as Norway maple (Pawłowski
\& Szczotka, 1997; Pawłowski, 2009), sycamore (Pawłowski \& Staszak, 2016) and European beech (Szczotka et al., 2003; Pawłowski, 2007). Seeds acquire dormancy during the maturation phase of development, and for germination to occur, they require a special treatment, e.g. cold stratification (Staszak \& Pawłowski, 2014; Staszak et al., 2019). European beech is an important forest tree species and a valuable biocoenotic component covering $4.1 \%$ of the forest area in Europe and gradually gaining importance 
in European forestry (Suszka et al., 1996). As the seed harvest appears irregularly every 5-10 years, appropriate storage without loss of viability of these sensitive intermediate seeds and proper stratification conditions are necessary for the establishment of good quality seedlings.

Imbalance in plant hormones, mainly abscisic (ABA) and gibberellic (GA) acids, is consider to be a main factor regulating dormancy (Luckwill, 1952). $\mathrm{ABA}$ is an inhibitor of germination responsive for dormancy induction and maintenance (Hilhorst, 1995). Page-Degivry et al. (1997) showed that during dormancy breaking of beech seeds the level of ABA decreased what was related to the diminishing of ABA synthesis by oxidation processes. To maintain dormancy, however, de novo synthesis of ABA in the embryo was necessary (Le Page-Degivry et al., 1997). Results of Pawłowski (2007) confirmed negative role of ABA and positive of GA on beech seed dormancy breaking. It has been indicated that in dormancy breaking of beech seeds, the ABA signal transduction pathway FsPP2C1 and FsPP2C2 phosphatases (Lorenzo et al. 2001, 2002; Gonzalez-Garcia et al. 2006; Saavedra et al. 2010), and FsPK1 and FsPK4 kinases (Lorenzo et al. 2003; Reyes et al. 2006; Jiménez et al., 2006) are involved. Jimenez et al. (2006) showed that FsPK4 is a member of the serine/threonine-protein kinases, and its expression is related to the maintenance of seed dormancy. They indicated that dormancy breaking is connected with a decrease in FsPK4 expression, which is related to a decrease in ABA level. GA addition also caused a reduction in FsPK4 expression (Jiménez et al., 2006).

Regulation of dormancy by ABA is also carried out through transcription factors and regulatory proteins. ABA insensitive 5 (ABI5) transcription factor plays a main role in expression of $\mathrm{ABA}$ regulated genes as a transcription factor binding to their promoters (Finkelstein \& Lynch, 2000; Nakamura et al., 2001). In Arabidopsis thaliana seeds of which represent non-deep physiological dormancy, ABI5 accumulated in dry seeds or young seedlings after ABA treatment (Finkelstein \& Lynch, 2000; Lopez-Molina et al., 2001; Piskurewicz et al., 2008). After imbibition or removal of exogenous ABA, ABI5 proteins are rapidly degraded. ABA added prevents germination and stimulates the de novo accumulation of ABI5 (Lopez-Molina et al., 2001, 2002). Piskurewicz et al. (2008) showed that the GA signalling repressor RGL2 inhibits Arabidopsis thaliana seed germination by stimulating ABA synthesis and ABI5 activity. They thereby showed the link between hormonal pathways regulating seed germination.

A number of recent studies have linked 14-3-3 proteins to ABA signalling, a few with its role in seed germination (Testerink et al., 2002; Schoonheim et al., 2007). 14-3-3 proteins act as a modulator of the activity of target proteins by attaching to their phosphorylated motifs (Ferl, 1996). In plants, 14-3-3 proteins take part in the regulation of an expanding catalogue of physiological functions, such as plant development and response to stress conditions (Roberts, 2003; Denison et al., 2011; de Boer et al., 2013). They can modulate signalling pathways, which transduce inputs from the environment, and also downstream proteins that elicit the physiological response (Denison et al., 2011). 14-3-3 proteins interact specifically with ABI5 (Schultz et al., 1998; Jakoby et al., 2002), leading to alterations in the transcription of ABA-responsive genes. Additionally, in barley, gibberellins influenced 14-3-3 protein accumulation, which suggests that 14-3-3 proteins take part in cross-talk of the hormonal pathways of antagonistically acting ABA and GA (Schoonheim et al., 2009).

Gibberellins play a crucial role in dormancy breaking, as they are promoters of germination (see review by Shu et al., 2016). Transcription of the gene encoding GA-20-oxidase, the main enzyme in GA synthesis, was not indicated in dormant beech seeds, but appeared during stratification (Calvo et al., 2004). Proteins from the DELLA family (e.g. GAI, RGA and RGL) are negative regulatory elements of the GA signalling pathway. The role of RGA-Like 2 (RGL2) is particular because it acts as a repressor of seed germination (Lee et al., 2002; Cao et al., 2005), and is involved in up-regulation of genes associated with acquisition of dormancy (Stamm et al., 2012). In contrast, GA promotes seed germination by enhancing the proteasome-mediated destruction of RGL2 (Piskurewicz et al., 2008). Despite all of these findings, it remains unclear exactly how RGL2 suppresses germination (Wang \& Deng, 2011). It is known, however that RGL2 participates in the control of cell growth by inhibiting the gene transcription of cell wall modulators ALPHA EXPANSIN3 (EXPA3) and EXPA8 (Stamm et al., 2012).

Presented literature shows that both ABA and GA pathways are involved in the regulation of seed dormancy, however precise mechanism in tree seeds is still not yet well elucidated. We hypothesized that the mechanism of seed dormancy breaking differs according to seeds' dormancy depth, and is associated with modulation in hormone signalling. In the present study, the expression of the signalling factors in the ABA and GA pathways in beech seeds during deep physiological dormancy breaking caused by cold stratification was investigated. We found differences between seeds characterised by deep and non-deep dormancy. Unlike non-deep dormant seeds (e.g. Arabidopsis spp.), in beech seeds ABI5, 14-3-3 proteins and RGL2 were present during nearly the entire period of cold stratification, but with dormancy breaking and germination these proteins nearly disappeared. They were therefore likely responsible for maintenance of dormancy. 


\section{Methods}

European beech seeds (Fagus sylvatica L.) were collected in Baligród, Poland (49 $\left.20^{\prime} \mathrm{N} 22^{\circ} 17^{\prime} \mathrm{E}\right)$ in 2009. Seeds were dried to $9 \%$ water content and stored at $-3^{\circ} \mathrm{C}$. For dormancy breaking, seeds were imbibed and stratified at $3^{\circ} \mathrm{C}$ for 17 weeks in closed plastic trays and in the dark. In each week, embryo axes were isolated from intact seeds. Stratification was ended after reaching maximum seed germination. The germination test was performed on four samples of 50 seeds each at $3^{\circ} \mathrm{C}$ and in the dark (International Seed Testing Association, 1999). A seed was counted as germinated when the radicle protruded $5 \mathrm{~mm}$.

\section{Western blotting}

Embryo axes were isolated from dry, stratified and germinated beech seeds and stored at $-80^{\circ} \mathrm{C}$. Samples were ground in cooled mortar and incubated in acetone at $-20^{\circ} \mathrm{C}$. Samples were then washed several times in acetone and centrifuged $(20,800 \times \mathrm{g}$ for 5 min at $\left.4^{\circ} \mathrm{C}\right)$. The resulting pellets were dried in vacuum and suspended in extraction buffer (0.5 M Tris $\mathrm{pH} 6.8,10 \%$ SDS, 7\% glycerol, $0.015 \%$ DTT) and incubated for $10 \mathrm{~min}$ at $100^{\circ} \mathrm{C}$. Samples were centrifuged again $\left(20,800 \mathrm{x}\right.$ g for $10 \mathrm{~min}$ at $4^{\circ} \mathrm{C}$ ) (Laemmli, 1970). Supernatants were taken and protein content was determined with a Bradford (1976) assay. The same amount of $40 \mathrm{mg}$ protein was used for each sample.

Protein separations were carried out using SDSPAGE (12\%) on Mini Protean 3 (BioRad, Hercules, Ca, USA) with protein ladder marker SeedBlue, MagicMarkt (Life Technologies, Carlsbad, CA, USA). After electrotransfer onto a PVDF membrane (BioRad, Hercules, Ca, USA) was carried out at $260 \mathrm{~mA}$ for $75 \mathrm{~min}$ in transfer buffer (25 mM Tris, $192 \mathrm{mM}$ glycine, $20 \%$ [v/v] methanol, $\mathrm{pH} 8,7)$, membranes were blocked overnight with TBS-T and 5\% BSA and incubated with primary rabbit polyclonal antibody. Primary antibodies were used against ABI5, 14-3-3 proteins and RGL2 (Agrisera, Vännäs, Sweden), in 1:7500 dilution. Bound antibodies were detected via anti-rabbit horseradish peroxidase conjugated secondary antibody (diluted 1:50,000 for ABI5, and 1:30,000 for 14-3-3 and RGL2) and visualised with chemiluminescent reagent Clarity (Bio-Rad, Hercules, Ca, USA). Signal was detected on X-ray film (Kodak, Rochester, NY, USA), which was afterwards scanned with Image Scanner III (GE Healthcare, Little Chalfont, UK) in the LabScan programme (GE Healthcare, Little Chalfont, UK). Patterns from three independent biological samples were aligned and normalised spot volumes of the bands were determined. Statistical analyses were carried out using ANOVA and the Tukey-Kramer HSD test (JMP software, SAS Institute, Cary, NC, USA). Results were considered significant for $\mathrm{P}<0.05$. The data are presented in relative units calculated as the intensity (density) and the area of the band.

\section{RNA extraction and reverse transcription}

Total RNA was extracted from three biological replicates of dry beech seeds and seeds collected every week of stratification. RNA was extracted according to the method of Chang et al. (1993), modified with an additional chloroform extraction. The RNA yields were measured three times with $\mathrm{OD}_{260}$ analysis using NanoDrop 2000c (ThermoScientific, Waltham, MA USA). The RNA samples were treated with RQ1 RNase-free DNase (Promega, Fitchburg, WI, USA). The first strand cDNAs for each sample were synthesised using $3 \mu \mathrm{g}$ of total RNA with the GoScript $^{\mathrm{TM}}$ Reverse Transcription System (Promega, Fitchburg, WI, USA), following the manufacturer's recommendations.

\section{Quantification of gene expression}

Analysis of mRNA relative abundance on the basis of accessible data from NCBI database was done for the following transcripts: 14-3-3, ABI5 and tubulin. The real-time reverse-transcription quantitative PCR analysis (RT-qPCR) was used for the quantification of $A B I 5,14-3-3$ and tubulin (with primers designed for this study; see Table 1) expression during breaking of deep physiological dormancy in beech seeds. All genes of interest were analysed in three replicates using different embryo pools. Each of the three replicates was analysed twice, to confirm results obtained

Table 1. Details of primers used for real-time reverse transcription PCR analysis

\begin{tabular}{|c|c|c|c|c|c|}
\hline $\begin{array}{l}\text { Sequence } \\
\text { number }\end{array}$ & Transcript & Sequence & AT & MT & $\begin{array}{l}\text { Amplicon } \\
\text { length }\end{array}$ \\
\hline AJ586516 & $\begin{array}{l}\text { Fagus sylvatica partial 14.3.3-1 mRNA for 14-3-3 } \\
\text { protein }\end{array}$ & $\begin{array}{l}\text { F: ACTGGTGCTGAGAGGAAGGA } \\
\text { R: TGCAAGCACGATCAGGTGAG }\end{array}$ & $53.8^{\circ} \mathrm{C}$ & $88.0^{\circ} \mathrm{C}$ & 169 bp \\
\hline DQ487781 & Fagus sylvatica putative tubulin alpha 1 chain, mRNA, & $\begin{array}{l}\text { F: GCACTGGTTCTGGTCTTGGA } \\
\text { R: CACTTGAGAGACAAGGCGGT }\end{array}$ & $53.8^{\circ} \mathrm{C}$ & $88.5^{\circ} \mathrm{C}$ & $272 \mathrm{bp}$ \\
\hline FR614636 & $\begin{array}{l}\text { Fagus sylvatica WZOAFSCA cDNA ( } 83 \% \text { similarity to } \\
\text { A. thaliana NM_129185.3) }\end{array}$ & $\begin{array}{l}\text { F: ACTGCTTCCTTCCCCTACCT } \\
\text { R: ACACAGACTGGTCCATGGTAA }\end{array}$ & $53.8^{\circ} \mathrm{C}$ & $85.0^{\circ} \mathrm{C}$ & 206 bp \\
\hline
\end{tabular}


from separate embryo pools. The duplicates gave one data point for one replicate and three replicates were used to calculate the mean. The gene for tubulin was used as the internal standard in RT-qPCR. For quantification, RT-qPCR was performed using the Rotor-Gene 6000 (Qiagen, Hilden, Germany) and AmpliQ Real-time PCR SYBR Green (AL1000-10, Novazym, Poznań, Poland). RT-qPCR was performed

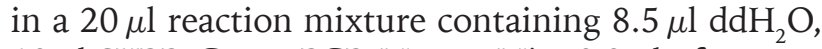
$10 \mu$ l SYBR-Green PCR Master Mix, $0.3 \mu$ l of reverse and forward primer mix $(5 \mu \mathrm{M})$ for the analysed gene (Table 1), and $1.2 \mu \mathrm{l}$ of template cDNA. The PCR conditions included $15 \mathrm{~min}$ of pre-denaturation at $94^{\circ} \mathrm{C}, 35$ cycles of $20 \mathrm{~s}$ at $95^{\circ} \mathrm{C}, 20 \mathrm{~s}$ at $53.8^{\circ} \mathrm{C}$ and 30 $\mathrm{s}$ at $72^{\circ} \mathrm{C}$, followed by $10 \mathrm{~min}$ at $72^{\circ} \mathrm{C}$. The melting protocol was run after each PCR and consisted of the temperature being held for 2 min and then heating from annealing temperature of the analysed gene to $94^{\circ} \mathrm{C}$, holding each temperature for $0.1 \mathrm{~s}$ while monitoring fluorescence.

The method used for gene quantification was based on a standard curve. Standard curves were constructed for each individual gene, using 10-fold serial dilutions of corresponding PCR products of known concentration. The dilutions were frozen and a single one was used in every real-time PCR run to be a point of reference for the standard curve. The transcript concentration for each gene calculated from the standard curve by software was normalised according to the relative concentration of the internal tubulin. The relative amount of each gene was calculated by dividing the quantity of the target gene by the quantity of the standard gene. The transcript level obtained for each cDNA sample was then related to each sample of germinated seeds.

Data describing relative expression level for 14-33 and ABI5 mRNA were analysed using the JMP12 (SAS, Cary, NC, USA) software package. Data obtained from RT-qPCR for 14-3-3 mRNA were normally distributed and were analysed with one-way analysis of variance (ANOVA), whereas data for ABI5 mRNA were not normally distributed and were analysed with Kruskall-Wallis one-way ANOVA on Ranks. When statistical differences occurred, data were analysed by multiple Tukey pair-wise comparisons. Differences of $\mathrm{P}<0.05$ were considered to be significant.

\section{Results}

Cold stratification at $3^{\circ} \mathrm{C}$ led to the breaking of dormancy and, consequently, to germination of European beech seeds (Figs 1-5). We observed that the first seeds started to germinate in week 7 of stratification, and by week 11 seeds reached $21 \%$ of germination. The experiment ended in week 17 when seeds reached $83 \%$ of germination.

\section{Immunodetection of ABI5, 14-3-3 and RGL2}

Immunodetection Western blot studies were undertaken to estimate ABI5, 14-3-3 and RGL2 accumulation in embryo axes of stratified European beech seeds. Western blot analysis indicated relatively high levels of transcription factor ABI5 in dormant dry seeds (Fig. 1). After one week of stratification of the beech seeds, we detected more than a twofold drop in

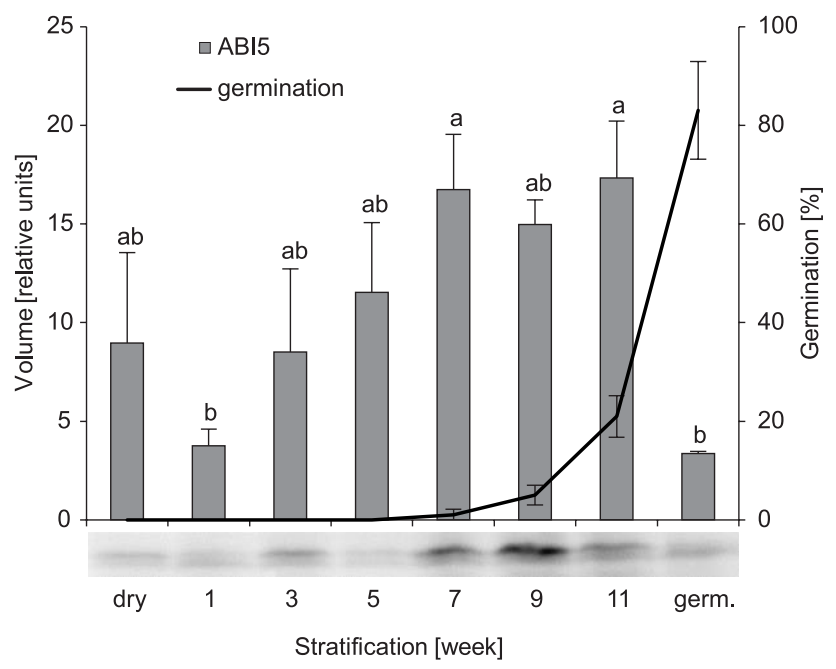

Fig. 1. Changes in accumulation of ABI5 protein in beech (Fagus sylvatica L.) seeds during dormancy breaking and germination. Western blot analyses were performed during stratification (dry - germinated seeds). Statistically significant differences were indicated with different letters. Data are mean \pm SD of three independent replications, $\mathrm{n}=3$

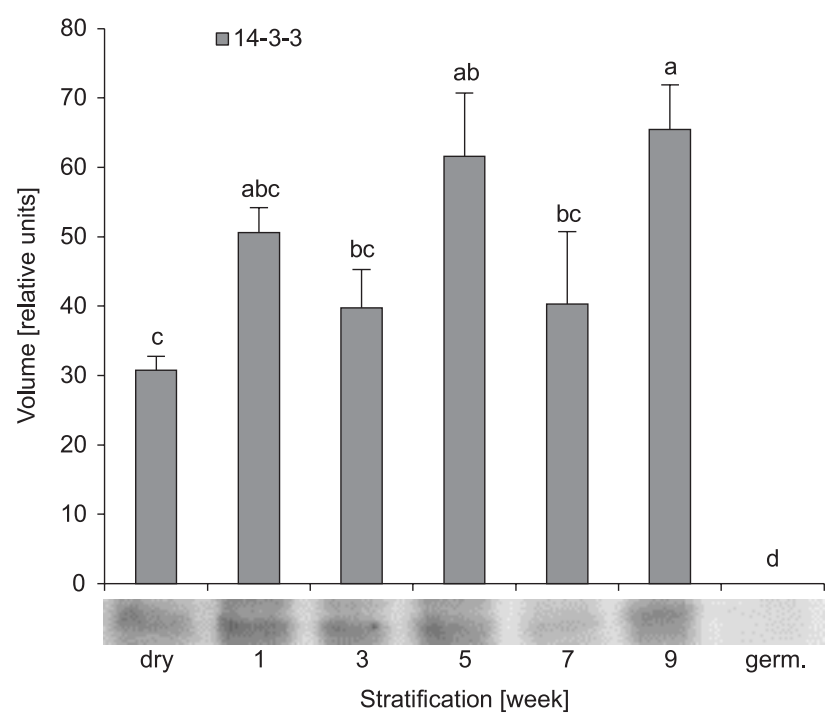

Fig. 2. Changes in accumulation of 14-3-3 proteins in beech (Fagus sylvatica L.) seeds during dormancy breaking and germination. Western blot analyses were performed during stratification (dry - germinated seeds). Statistically significant differences were indicated with different letters. Data are mean \pm SD of three independent replications, $\mathrm{n}=3$ 


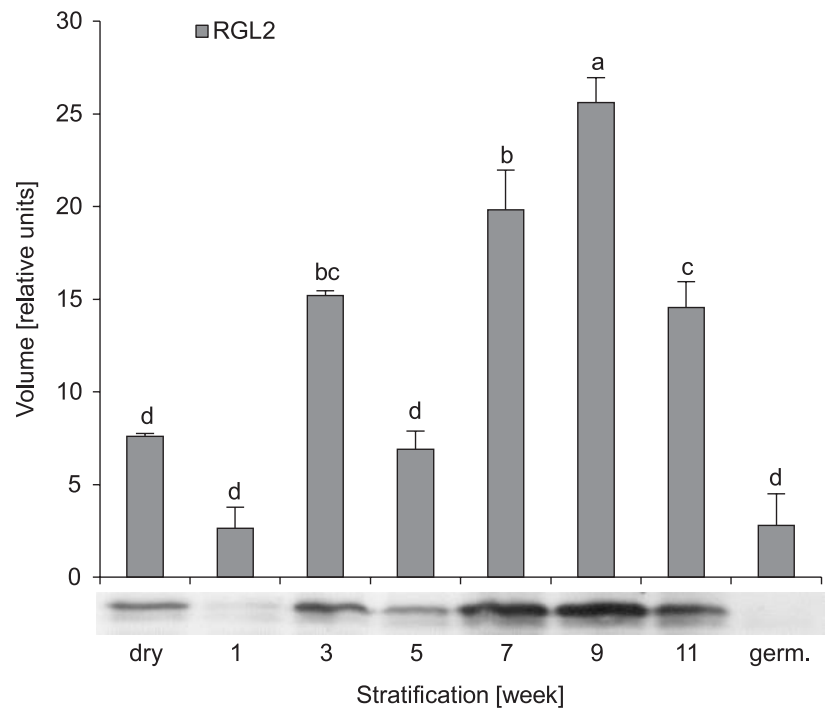

Fig. 3. Changes in accumulation of RGL2 protein in beech (Fagus sylvatica L.) seeds during dormancy breaking and germination. Western blot analyses were performed during stratification (dry - germinated seeds). Statistically significant differences were indicated with different letters. Data are mean \pm SD of three independent replications, $\mathrm{n}=3$

accumulation of ABI5. From week 3 through to week 7 of stratification, however, accumulation of ABI5 increased. Between weeks 7 and 11 ABI5 showed a similar level of accumulation, reaching its highest accumulation in week 11. In germinated seeds, accumulation of ABI5 dropped drastically to its lowest level.

Western blot analysis of 14-3-3 protein accumulation during dormancy breaking of beech seeds showed relatively low levels of these proteins in dormant dry seeds (Fig. 2). During stratification, the accumulation level of 14-3-3s varied but it reached its peaks in week 5 and 9 , in comparison to dormant dry seeds. In germinated beech seeds, 14-3-3 protein accumulation was not indicated.

Western blot analysis of RGL2 protein accumulation showed relatively low levels of this protein in dormant dry beech seeds (Fig. 3). After one week of stratification, we observed a statistically insignificant decrease in RGL2 accumulation. Levels increased irregularly until week 9 , when accumulation peaked. In week 11 of stratification, RGL2 protein accumulation levels dropped. In germinated beech seeds, accumulation of RGL2 reached its lowest level during whole stratification, being more than twofold lower than in dry seeds.

\section{Quantification of ABI5 and 14-3-3 gene expression}

Q-RT-PCR was used to analyse relative abundance of 14-3-3 and ABI5 transcripts in relation to

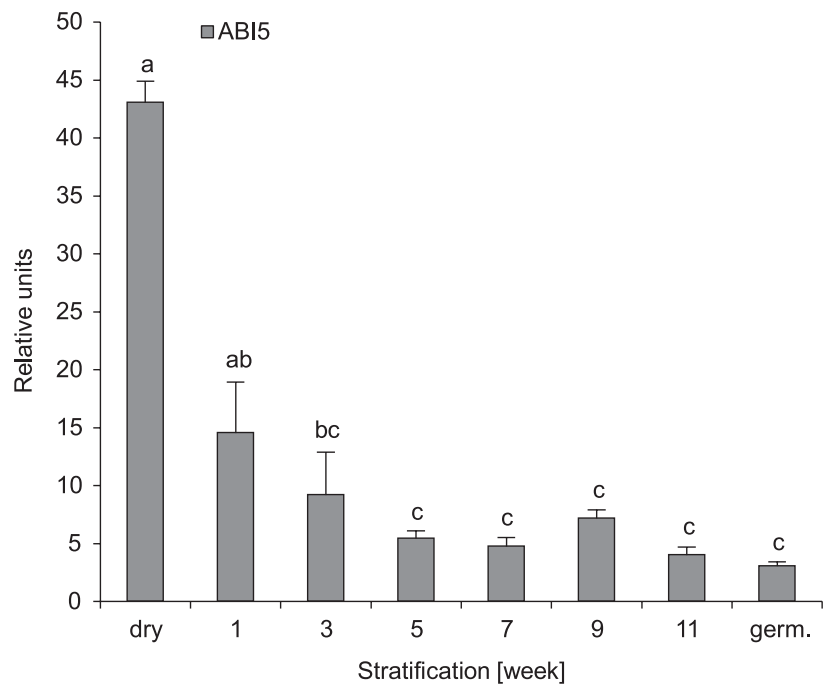

Fig. 4. Changes in accumulation of ABI5 mRNA in beech (Fagus sylvatica L.) seeds during dormancy breaking and germination. Statistically significant differences were indicated with different letters. Data are mean \pm SD of three independent replications, $\mathrm{n}=3$

transcripts of tubulin (Table 1). ABI5 mRNA was present in all analysed samples of beech seeds, and its relative abundance (RA) was related to the week of the seeds stratification $(\mathrm{P}<0.001)$. The highest RA of $A B I 5$ was observed in dry seeds, and it then decreased according to the week of stratification. Relative abundance of transcripts for 14-3-3 mRNA was also stage/time dependent $(\mathrm{P}=0.018)$. The highest RA was detected in dry seeds and was three times higher than after one week of stratification. RA of 14-3-3 mRNA decreased during stratification but was present at all time points of stratification and also in germinated plants (Figs 4 and 5).

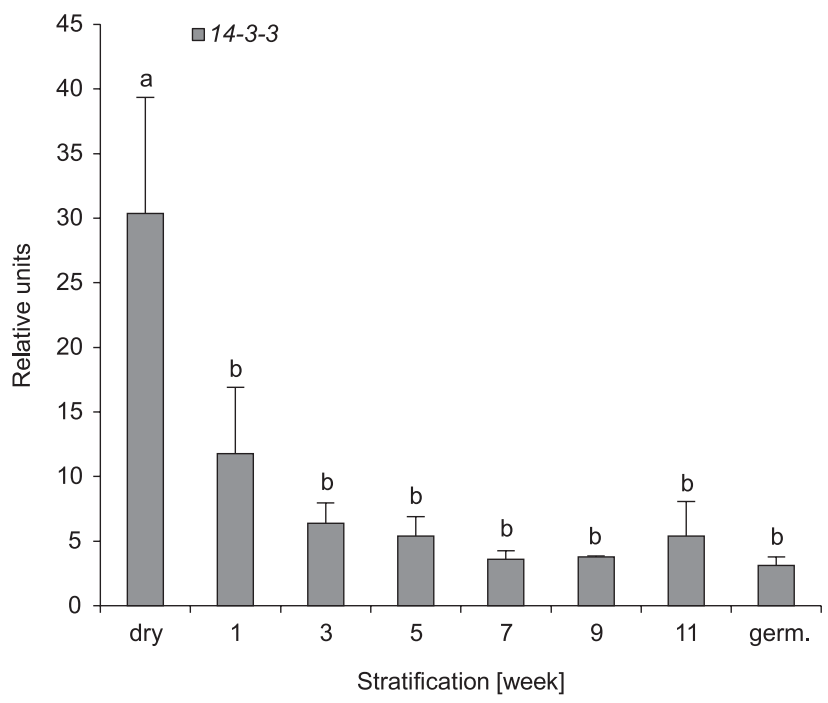

Fig. 5. Changes in accumulation of 14-3-3 mRNA in beech (Fagus sylvatica L.) seeds during dormancy breaking and germination. Statistically significant differences were indicated with different letters. Data are mean \pm SD of three independent replications, $n=3$ 


\section{Discussion}

The seeds of many species are characterised by dormancy phenomena, traits which protect seeds against germination in favourable conditions to avoid subsequent seedling growth in unfavourable conditions (Black et al., 2008). Most broadleaf trees in temperate climates are characterised by deep physiological dormancy localised in the embryo (Pawłowski, 2010). The mechanism of deep physiological dormancy appears to be related to reversible metabolic processes (Black et al., 2008). Embryos excised from these seeds either do not grow or produce abnormal seedlings (Finch-Savage \& Leubner-Metzger, 2006). Seeds possessing deep physiological embryo dormancy can be stimulated to germinate by cold stratification (Baskin \& Baskin, 2004) which mimics natural winter conditions.

Hormonal imbalance between germination inhibitors (e.g. ABA) and stimulators (e.g. GA) is suggested to be a main factor controlling dormancy status (Lukwill 1952). Non-deep physiological dormancy of Arabidopsis spp. seeds is associated with a high level of $A B A$ and during dormancy breaking the level of ABA decreased (Piskurewicz et al., 2008). The decrease in the depth of dormancy of beech seeds, caused by cold stratification, has been observed to be directly proportional to the drop in endogenous ABA content, however some ABA content was still present till germination (Eliasova et al., 2015). ABI5 transcription factor and 14-3-3 proteins take part in ABA signalling by inducing expression of ABA responsible genes (Schoonheim et al., 2007), which results in suppression of germination (Piskurewicz et al., 2009). In the present study, we observed that accumulation of ABI5 decreased in beech seeds after one week of stratification, but afterwards it increased and stayed at a high level until seeds lost dormancy and began germination. Our expression study showed that the $A B I 5$ genes are transcribed mostly in dormant dry beech seeds. During the following weeks of stratification, relative abundance of analysed transcripts decreased gradually, but ABI5 was still present even in germinated seeds. High $A B I 5$ expression in dry seeds and decrease at the beginning of stratification coincided with ABA content changes (Eliasova et al., 2015). It can be suggested that mother-deposited ABI5 protein was degraded at the beginning of stratification and with stratification progress de novo translation of ABI5 protein on the basis of deposited mRNA occurred. The high accumulation of ABI5, in some extent of ABI5, and presence of ABA (Eliasova et al., 2015), during stratification could be associated with maintenance of seed dormancy. De novo ABA synthesis was also observed during dormancy alleviation by temperature of $20^{\circ} \mathrm{C}$ in sunflower seeds (Xia et al., 2019). In germinated beech seeds, ABI5 and ABI5 accumulation dropped to a very low level. It can therefore be concluded that as a result cold stratification leads to a decrease in ABI5/ABI5 accumulation, which likely blocks ABA-dependent gene expression and promotes dormancy breaking and, consequently, seed germination. Xia et al. (2019) demonstrated that ABI5 moves during dormancy alleviation from nucleus to the cytoplasm, where it is degraded probably by oxidation and/or ubiquitination. The profile of ABI5 protein accumulation in European beech seeds differs from that of Arabidopsis thaliana (Piskurewicz et al., 2008) and Norway maple seeds (Staszak et al., 2017). Unlike the beech, in Arabidopsis ABI5 protein has been shown to reach its maximum rate of accumulation in dry seeds and at the beginning of imbibition, after which it disappeared. In Norway maple seeds $\mathrm{ABI} 5$ protein reached its maximum at the beginning of stratification, after which it decreases gradually. These differences in ABI5 accumulation are likely associated with the depth of dormancy. In germinated beech seeds, accumulation of ABI5 was relatively low, as was also observed in Norway maple (Staszak et al., 2017) and Arabidopsis seeds (Lopez-Molina et al., 2001; Piskurewicz et al., 2008). Presence of $\mathrm{ABI} 5 / A B I 5$ after germination suggests that it is also involved in some post-germination events (Finkelstein \& Lynch, 2000; Lopez-Molina et al., 2001; Dai et al., 2013).

14-3-3 proteins modulate the activity of phosphorylated proteins (Ferl, 1996). In plants, they are implicated in an expanding list of physiological functions (see review by Denison et al., 2011). Among other functions, 14-3-3 proteins are involved in the ABA signal transduction pathway, leading to alteration in transcription (Roberts, 2003; Denison et al., 2011; de Boer et al., 2013). One potential point of 14-3-3 interaction is with the ABI5 transcription factor (Denison et al., 2011). In the present study, changes in accumulation of 14-3-3 proteins correlated with changes in accumulation of ABI5 during cold stratification of beech seeds. Interestingly, the expression of 14-3-3 possessed also a similar pattern to that of ABI5. In Norway maple seeds, accumulation of ABI5 and 14-3-3 also coincided and decreased during stratification (Staszak et al., 2017). It has been suggested that 14-3-3 proteins may act as adaptors between barley VP1 (homolog of ABI3 in Arabidopsis) and ABI5 (Himmelbach et al., 2003). ABA treatment inhibited the proteolysis of 14-3-3 proteins in the embryonic root (Himmelbach et al., 2003; Schoonheim et al., 2007). Schoonheim et al. (2009) suggested that 14-3-3 proteins interact with PKABA1 phosphatase kinases and transcription factors of the $A B F /$ AREB/ABI5 family in cross-talk between the hormonal pathways of $A B A$ and GA. The present results showed the coincidence between ABI5 and 14-3-3 
protein and transcript patterns in the seed dormancy breaking caused by cold stratification, but details concerning the role of 14-3-3/14-3-3 in the action of ABA remain a mystery.

GA promotes germination via proteasome-mediated destruction of DELLA repressors, such as RGL2 (Piskurewicz et al., 2009). RGL2 repress activation of the EXPANSIN2 promoter by NAC transcription factors inhibiting Arabidopsis seed germination (Sánchez-Montesino et al., 2019). In the present study, we observed that RGL2 accumulation generally increased during stratification of European beech seeds, but decreased with dormancy breaking and was lowest in germinated seeds. This pattern was similar to that observed for ABI5. Comparison of these results with results of an investigation carried out with Norway maple seeds showed a similar accumulation pattern of RGL2 during stratification, although the decrease was observed earlier in Norway maple seeds (Staszak et al., 2017). Germinated seeds in both species showed relatively low levels of RGL2 protein accumulation. These results differ from those obtained by Wang et al. (2013), where the level of RGL2 was found to decrease directly after imbibition of Pyrus pyrifolia nutlets. Interestingly, this decrease was inhibited by ABA (Wang et al., 2013). The expression of RGL2 was induced during chilling-induced dormancy release in Arabidopsis seeds but downregulated in the presence of ethylene (Wang et al., 2018). Piskurewicz et al. (2009, 2008) indicated that RGL2 inhibited germination by stimulating both ABI5 and ABI3 activity, and ABA synthesis. Xia et al. (2019) found that the exclusion of RGL2 from the nucleus and cytoplasmic degradation allows an increase in sensitivity to GAs favouring seed dormancy alleviation. It can be concluded that RGL2 takes part in the repression of germination in beech seeds. We suggest that this is meant to achieve inhibition of germination through de novo protein synthesis.

\section{Acknowledgements}

The authors wish to thank Sylwia Masłowska for technical support.

This work was supported by the National Science Centre, Poland; under Grant 2011/01/B/NZ9/02868 to T.A.P.; and Ministry of Science and Higher Education, Poland; under Grant for Young Scientist to A.M.S.

\section{References}

Baskin J \& Baskin C (2004) A classification system for seed dormancy. Seed Science Research 14: $1-16$.
Black M, Bewley JD \& Halmer P (2008) The encyclopedia of seeds. Science, Technology and Uses. CABI, Wallingford, UK.

de Boer AH, van Kleeff PJM \& Gao J (2013) Plant 14-3-3 proteins as spiders in a web of phosphorylation. Protoplasma 250: 425-440.

Bradford MM (1976) A rapid and sensitive method for the quantitation of microgram quantities of protein utilizing the principle of protein-dye binding. Analytical Biochemistry 72: 248-254.

Calvo A, Nicolas C, Nicolas G \& Rodriguez D (2004) Evidence of a cross-talk regulation of a GA 20-oxidase (FsGA20ox1) by gibberellins and ethylene during the breaking of dormancy in Fagus sylvatica seeds. Physiologia Plantarum 120: 623-630.

Cao D, Hussain A, Cheng H \& Peng J (2005) Loss of function of four DELLA genes leads to lightand gibberellin-independent seed germination in Arabidopsis. Planta 223: 105-113.

Chang S, Puryear J \& Cairney J (1993) A simple and efficient method for isolating RNA from pine trees. Plant Molecular Biology Reporter 11: 113116.

Dai M, Xue Q, Mccray T, Margavage K, Chen F, Lee J-H, Nezames CD, Guo L, Terzaghi W, Wan J, Deng XW \& Wang H (2013) The PP6 phosphatase regulates ABI5 phosphorylation and abscisic acid signaling in Arabidopsis. The Plant Cell 25: 517-534.

Denison FC, Paul A-L, Zupanska AK \& Ferl RJ (2011) 14-3-3 proteins in plant physiology. Seminars in Cell \& Developmental Biology 22: 720-727.

Eliasova K, Pesek B \& Vondrakova Z (2015) Storage compounds, $\mathrm{ABA}$ and fumarase in Fagus sylvatica embryos during stratification. Dendrobiology 74 : 25-33.

Ferl RJ (1996) 14-3-3 proteins and signal transduction. Annual Review of Plant Physiology and Plant Molecular Biology 47: 49-73.

Finch-Savage W \& Leubner-Metzger G (2006) Seed dormancy and the control of germination. New Phytologist 171: 501-523.

Finkelstein RR \& Lynch TJ (2000) The Arabidopsis abscisic acid response gene ABI5 encodes a basic leucine zipper transcription factor. The Plant Cell 12: 599-609.

Hilhorst HWM (1995) A critical update on seed dormancy. I. Primary dormancy. Seed Science Research 5: 61-73.

Himmelbach A, Yang Y \& Grill E (2003) Relay and control of abscisic acid signaling. Current Opinion in Plant Biology 6: 470-479.

International Seed Testing Association (1999) International rules for seed testing. Seed Science Technology 27: 1-133.

Jakoby M, Weisshaar B, Dröge-Laser W, Vicente-Carbajosa J, Tiedemann J, Kroj T, Parcy F \& bZIP Re- 
search Group (2002) bZIP transcription factors in Arabidopsis. Trends in Plant Science 7: 106-111.

Jiménez JA, Rodríguez D, Lorenzo O, Nicolás G \& Nicolás C (2006) Characterization of a protein kinase (FsPK4) with an acidic domain, regulated by abscisic acid and specifically located in Fagus sylvatica L. seeds. Journal of Plant Physiology 163: 761-769.

Laemmli UK (1970) Cleavage of structural proteins during the assembly of the head of bacteriophage T4. Nature 227: 680-685.

Le Page-Degivry MT, Garello G \& Barthe P (1997) Changes in abscisic acid biosynthesis and catabolism during dormancy breaking in Fagus sylvatica embryo. Journal of Plant Growth Regulation 16: $57-61$

Lee S, Cheng H, King KE, Wang W, He Y, Hussain A, Lo J, Harberd NP \& Peng J (2002) Gibberellin regulates Arabidopsis seed germination via RGL2, a GAI/RGA-like gene whose expression is up-regulated following imbibition. Genes \& Development 16: 646-658.

Lopez-Molina L, Mongrand S \& Chua N-H (2001) A postgermination developmental arrest checkpoint is mediated by abscisic acid and requires the ABI5 transcription factor in Arabidopsis. Proceedings of the National Academy of Sciences of the United States of America 98: 4782-4787.

Luckwill L (1952) Growth-inhibiting and growth-promoting substances in relation to the dormancy and after-ripening of apple seeds. The Journal of Horticultural Science \& Biotechnology 27: 53-67.

Nakamura S, Lynch TJ \& Finkelstein RR (2001) Physical interactions between ABA response loci of Arabidopsis. Plant Journal 26: 627-635.

Pawłowski TA (2007) Proteomics of European beech (Fagus sylvatica L.) seed dormancy breaking: Influence of abscisic and gibberellic acids. Proteomics 7: 2246-2257.

Pawłowski TA (2009) Proteome analysis of Norway maple (Acer platanoides L.) seeds dormancy breaking and germination: influence of abscisic and gibberellic acids. BMC Plant Biology 9: 48.

Pawłowski TA (2010) Proteomic approach to analyze dormancy breaking of tree seeds. Plant Molecular Biology 73: 15-25.

Pawłowski TA \& Staszak AM (2016) Analysis of the embryo proteome of sycamore (Acer pseudoplatanus L.) seeds reveals a distinct class of proteins regulating dormancy release. Journal of Plant Physiology 195: 9-22.

Pawłowski T \& Szczotka Z (1997) Qualitative changes in protein content during cold and warm stratification of Norway maple (Acer platanoides L.) seeds. Seed Science Research 7: 385-390.

Piskurewicz U, Jikumaru Y, Kinoshita N, Nambara E, Kamiya Y \& Lopez-Molina L (2008) The gibberel- lic acid signaling repressor RGL2 inhibits Arabidopsis seed germination by stimulating abscisic acid synthesis and ABI5 activity. The Plant Cell 20: 2729-2745.

Piskurewicz U, Turečková V, Lacombe E \& Lopez-Molina L (2009) Far-red light inhibits germination through DELLA-dependent stimulation of ABA synthesis and $\mathrm{ABI} 3$ activity. The EMBO Journal 28: 2259-2271.

Roberts MR (2003) 14-3-3 proteins find new partners in plant cell signalling. Trends in Plant Science 8: 218-223.

Sánchez-Montesino R, Bouza-Morcillo L, Marquez J, Ghita M, Duran-Nebreda S, Gómez L, Holdsworth MJ, Bassel G \& Oñate-Sánchez L (2019) A regulatory module controlling GA-mediated endosperm cell expansion is critical for seed germination in Arabidopsis. Molecular Plant 12: 71-85.

Schoonheim PJ, Costa Pereira DDA \& De Boer AH (2009) Dual role for 14-3-3 proteins and ABF transcription factors in gibberellic acid and abscisic acid signalling in barley (Hordeum vulgare) aleurone cells. Plant, Cell \& Environment 32: 439-447.

Schoonheim PJ, Sinnige MP, Casaretto JA, Veiga $\mathrm{H}$, Bunney TD, Quatrano RS \& de Boer AH (2007) 14-3-3 adaptor proteins are intermediates in ABA signal transduction during barley seed germination. The Plant Journal: For Cell and Molecular Biology 49: 289-301.

Schultz TF, Medina J, Hill A \& Quatrano RS (1998) 14-3-3 proteins are part of an abscisic acid-VIVIPAROUS1 (VP1) response complex in the Em promoter and interact with VP1 and EmBP1. The Plant Cell 10: 837-847.

Shu K, Liu X, Xie Q \& He Z (2016) Two faces of one seed: hormonal regulation of dormancy and germination. Molecular Plant 9: 34-45.

Stamm P, Ravindran P, Mohanty B, Tan EL, Yu H \& Kumar PP (2012) Insights into the molecular mechanism of RGL2-mediated inhibition of seed germination in Arabidopsis thaliana. BMC Plant Biology 12: 179 .

Staszak AM, Rewers M, Sliwinska E, Klupczyńska EA \& Pawłowski TA (2019) DNA synthesis pattern, proteome, and ABA and GA signalling in developing seeds of Norway maple (Acer platanoides). Functional Plant Biology 46: 152-164.

Staszak AM, Guzicka M \& Pawłowski TA (2017) Signalling regulators of abscisic and gibberellic acid pathways are involved in dormancy breaking of Norway maple (Acer platanoides L.) seeds. Acta Physiologiae Plantarum 39: 251.

Staszak AM \& Pawłowski TA (2014) Proteomic analysis of embryogenesis and the acquisition of seed dormancy in Norway maple (Acer platanoides L.). 
International Journal of Molecular Sciences 15: 10868-10891.

Suszka B, Muller C, Bonnet-Masimbert M (1996) Seeds of forest broadleaves. From harvest to sowing. INRA, Paris, France.

Szczotka Z, Pawłowski T \& Krawiarz K (2003) Proteins and polyamines during dormancy breaking of European beech (Fagus sylvatica L.) seeds. Acta Physiologiae Plantarum 25: 423-435.

Testerink C, Zeijl MJ van, Drumm K, Palmgren MG, Collinge DB, Kijne JW \& Wang M (2002) Post-translational modification of barley 14-3-3A is isoform-specific and involves removal of the hypervariable C-terminus. Plant Molecular Biology 50: 535-542.

Wang X, Yesbergenova-Cuny Z, Biniek C, Bailly C, El-Maarauf-Bouteau H \& Corbineau F (2018)
Revisiting the role of ethylene and $\mathrm{N}$-end rule pathway on chilling-induced dormancy release in Arabidopsis seeds. International Journal of Molecular Sciences 19: 3577.

Wang Y, Dai M, Zhang S \& Shi Z (2013) Exploring the hormonal and molecular regulation of sand pear (Pyrus pyrifolia) seed dormancy. Seed Science Research 23: 15-25.

Wang F \& Deng XW (2011) Plant ubiquitin-proteasome pathway and its role in gibberellin signaling. Cell Research 21: 1286-1294.

Xia Q, Ponnaiah $\mathrm{M}$, Thanikathansubramanian $\mathrm{K}$, Corbineau F, Bailly C, Nambara E, Meimoun P \& El-Maarouf-Bouteau H (2019) Re-localization of hormone effectors is associated with dormancy alleviation by temperature and after-ripening in sunflower seeds. Scientific Reports 9: 4861. 